\title{
IMPLEMENTASI SISTEM PENJUALAN ONLINE BERBASIS E-COMMERCE PADA USAHA UKM IKE SUTI MENGGUNAKAN METODE WATERFALL
}

\author{
IMPLEMENTATION OF ONLINE SALES SYSTEM BASED ON E-COMMERCE IN \\ UKM BUSINESSES IKE SUTI USING THE WATERFALL METHOD
}

\begin{abstract}
Risald ${ }^{1)}$ Lidwina Sriwidya Lafu ${ }^{2)}$
Program Studi Teknologi Informasi, Fakultas Pertanian, Universitas Timor Jl. Km. 09, Kelurahan Sasi, Kecamantan Kota Kefamemanu, TTU, NTT, 85613

Copyright (C2021, JITU, Submitted:11 Desember 2020; Revised: 03 February 2021; Accepted: 14 February 2021; Published: 01 Maret 2021

Abstract - With their services in the form of E-Commerce then all services performed by the customer can be immediately acted upon, so the company will be able to provide the best service and fast. The problem in buying and selling activities carried out by UKM at this time is that sales are still not done online. Therefore, the author wants to provide an online sales system that will be used as a place to promote goods that will be sold on the system. The Waterfall method is a software development that is carried out sequentially and very systematically. By using the Waterfall Method, the author will build an e-commerce-based online sales system software that can be used in UKM. This system has the convenience of marketing and selling products, it has the convenience of marketing and selling company-owned products with the UKM process with the process of buying and selling products, namely through direct payments. With the E-Commerce Web that utilizes the internet as a marketing medium, it can make it easier for shop owners to provide optimal service to consumers/customers and provide 24hour information and can be accessed anytime anywhere.
\end{abstract}

Keywords - UKM; Websites; E-commerce; Waterfall Method.

Abstrak - Dengan adanya layanan jasa berupa $E$-Commerce maka segala layanan yang dilakukan oleh para pelanggan dapat segera ditindaklanjuti, sehingga perusahaan akan mampu memberikan pelayanan yang terbaik dan cepat. Adapun masalah dalam aktivitas jual beli yang dilakukan oleh UKM saat ini yaitu penjualan yang masih belum dilakukan secara daring (online). Oleh karena itu maka penulis ingin membuatkan suatu sitem penjualan online yang akan digunakan sebagai tempat untuk mempromosikan barang-barang yang akan dijual pada sistem tersebut. Metode Waterfall adalah pengembangan perangkat lunak yang dilakukan secara berurutan dan sangat sistematis. Dengan menggunakan Metode Waterfall, penulis akan membangun sebuah perangkat lunak (software) sistem penjualan online berbasis e-commerce yang dapat digunakan pada UKM. Sistem ini memiliki kemudahan untuk memasarkan dan menjual produk memiliki kemudahan untuk memesarkan dan menjual produk milik perusahaan dengan proses UKM dengan proses transaksi jual beli produk yaitu melalui pembayaran secara langsung. Dengan adanya Web $E$ Commerce yang memanfaatkan internet sebagai media pemasaran, dapat memudahkan pemilik toko untuk memberikan pelayanan terhadap konsumen/pelanggan secara optimal dan memberikan informasi 24 jam serta dapat diakses kapan saja dimana saja.

Kata kunci - UKM; Website; E-commerce; Metode Waterfall.

\section{PENDAHULUAN}

Sejalan dengan cepatnya perkembangan bidang teknologi, perusahaan-perusahaan yang termasuk dalam industri kecil, menengah maupun besar, yang merupakan salah satu dari sekian banyak pelaku dan penunjang kegiatan ekonomi di negeri ini, semakin dipacu untuk menggunakan teknologi yang maju sebagai senjata untuk tetap survive dan memenangkan persaingan yang kian hari terasa ketat dan keras. Oleh karena itu, teknologi web di internet memainkan peran yang sangat penting, yaitu memungkinkan organisasi atau perusahaan memasuki pasar dengan cara yang mudah, murah dan tanpa batasan geografis,

\footnotetext{
*) Penulis Korespondensi (Risald)
}

Email: Risald@gmail.com semuanya akan berada dalam apa yang dinamai ruang maya (Cyberspace). Dalam hal ini, organisasi atau perusahaan akan bersaing dengan pelaku bisnis yang lain di dunia maya (virtual world).

Akhir-akhir ini penggunaan internet yang mengurus kepada cyberspace, yang akan mendominasi seluruh kegiatan di atas permukaan bumi di masa kini maupun masa mendatang, yang secara umum akan berubah menjadi alat untuk persaingan antara perusahaan yang satu dengan yang lainnya. Ini pun akan membawa dampak yang sangat besar bagi setiap perusahaan. Dampak pada aspek persaingan adalah terbentuknya tingkat kompetisi yang semakin tajam yang membuat perusahaan dalam globalisasi ekonomi ini membuat perubahan menjadi konstan, pesat redikal dan serentak. Sehingga perusahaan harus memiliki kemampuan yang cepat untuk beradaptasi terhadap perubahan yang terjadi 
sehingga perusahaan akan mampu bersaing dengan para kompetitinya.

Penggunaan teknologi diharapkan dapat memberikan manfaat yang besar terhadap dunia bisnis yang kompetitif tersebut, perusahaan yang mampu bersaing dalam kompetisi tersebut adalah perusahaan yang mampu mengimplementasikan teknologi ke dalam perusahaanya. Salah satu jenis implementasi teknologi dalam hal meningkatkan persaingan bisnis adalah dengan menggunakan electronic commerce (e-commerce) yaitu untuk memasarkan berbagai macam produk atau jasa, baik dalam bentuk fisik maupun digital. Dengan ini, $e-$ commerce didefenisikan sebagai proses pembelian atau penjualan antara dua belah pihak di dalam suatu perusahaan dengan adanya pertukaran barang, jasa atau informasi melalui media internet. Ternyata tidak mudah dalam mengimplemenatasikan e-commerce dikarenakan banyaknya faktor yang terkait dengan teknologi yang harus dikuasai. Dengan demikian ada tiga kategori dasar atau jenis-jenis e-commerce yaitu"Business To Costumer (B2C), Business To Business(B2B) dan Costumer To Costumer (C2C)" (Humdiana dan Indrayani, 2005).

Dengan adanya tiga kategori di atas, dapat memudahkan para pelaku bisnis untuk melakukan sasaran yang akan dituju, dengan demikian, "yang harus diingat dalam melangsungkan aktivitas bisnis $e$ commerce yaitu: adanya proses baik penjualan maupun pembelian secara elektronik, adanya konsumen atau perusahaan dan adanya jaringan penggunaan komputer secara on-line untuk melakukan transaksi bisnis" (Laudon dan Laudon dalam Handoko, 2001).

Disamping itu, bisnis e-commerce mempunyai beberapa keuntungan antara lain yaitu: "dapat memperluas jaringan mitra bisnis, jangkauan pemasaran menjadi semakin luas, aman secara fisik, efektif, efisien dan fleksibel. Selain itu terdapat kekurangan dalam bisnis e-commerce antara lain: meningkatkan individualism, terkadang menimbulkan kekecewaan dan tidak manusiawi". Dapat mendapatkan kepercayaan dalam e-commerce, ada beberapa prinsip yang harus dipenuhi, antara lain keterbukaan (business practice disclosure) yaitu akan melakukan transaksi sesuai dengan yang dijanjikan. Intergritas transaksi (transaction integrity) yaitu tagihan yang sesuai dengan transaksi. Dan juga perlindungan terhadap informasi (information protection) yaitu penjagaan informasi agar tidak jatuh ke pihak yang tidak berkaitan dengan bisnisnya.

Peningkatan transaksi menggunakan e-commerce oleh perusahaan merupakan indikasi bahwa manajemen memiliki komitmen terhadap pemanfaatan cara baru. Atau lebih tepat digambarkan sebagai suatu komitmen untuk memanfaatkan $e$ commerce di dalam pengembangan perusahaan. Selama ini, sistem penjualan yang digunakan oleh perusahaan hanya bersifat manual dan secara tertulis, yang tidak jarang cenderung menyesatkan. Dengan adanya layanan jasa berupa e-commerce yang dapat secara cepat dapat dinikmati oleh pelanggan maupun perusahaan sendiri, maka segala layanan yang diinginkan oleh para pelanggan dapat segera ditindaklanjuti dengan secepat mungkin, sehingga perusahaan tersebut akan mampu memberikan pelayanan yang terbaik dan tercepat bagi para pelanggan.

Adapun masalah dalam aktivitas jual beli yang dilakukan oleh UKM tersebut yaitu penjualan yang masih belum dilakukan secara daring (online) sehingga barang yang dijual tidak diketahui secara keseluruhan oleh masyarakat juga pendatang. Karena proses penjualan masih secara manual, penulis ingin membuatkan suatu sitem penjualan on-line yang akan digunakan sebagai tempat untuk mempromosikan barang-barang yang akan dijual pada sistem tersebut yang akan dapat dilihat oleh semua masyarakat baik dalam daerah maupun luar daerah. Metode Waterfall adalah pengembangan perangkat lunak yang dilakukan secara berurutan dan sangat sistematis. Dengan menggunakan metode Waterfall, penulis dapat membangun sebuah perangkat lunak (software) yang akan diusulkan pada UKM tersebut.

Berkaitan dengan masalah di atas maka penelitian ini difokuskan pada masalah pemanfaatan tujuan teknologi informasi yang dapat memberi dukungan aktif kelancaran usaha penjualan barang yang dilakukan oleh suatu UKM atau usaha rumahan yang yaitu Implementasi Sistem Penjualan On-line berbasis $E$ commerce pada Usaha Ume Ike Suti Menggunakan Metode Waterfall.

\section{METODE PENELITIAN}

\section{A. Pengertian Usaha Kecil dan Menengah (UKM)}

Usaha Kecil dan Menengah (UKM) adalah suatu bentuk usaha yang dilihat dari skalanya usaha rumah tangga dan usaha kecil hanya mempunyai pegawai antara 1-19 orang. Sementara usaha menengah mempunyai pegawai 20-99 orang. UKM ini telah terbukti merupakan salah satu bentuk usaha yang dapat bertahan dalam krisis ekonomi yang pernah terjadi di Indonesia

\section{B. Website}

Website adalah lokasi di internet yang menyajikan informasi sehubungan dengan profil pemilik situs. Website adalah suatu halaman yang memuat situs-situs web page yang berada di internet yang berfungsi sebagai media penyampaian informasi, komunikasi atau transaksi. (Hastanti R. P dkk, 2015)

\section{E-Commerce}

Perdagangan sebenarnya merupakan kegiatan yang dilakukan manusia sejak awal peradabannya. Sejalan dengan perkembangan manusia, cara dan sarana yang digunakan untuk berdagang senantiasa berubah. Bentuk perdagangan terbaru yang kian memudahkan penggunanya kini ialah e-commerce. E-commerce adalah sebuah transaksi penjualan yang dilakukan secara online yang hanya dilakukan oleh sebuah toko itu sendiri. Berikut adalah pengertian e-commerce menurut para ahli:

1. Menurut Laudon (1998)

E-commerce adalah suatu proses membeli dan menjual produk-produk secara elektronik oleh konsumen dan dari perusahaan ke perusahaan dengan computer sebagai perantara transaksi bisnis.

\section{Onno W. Purbo}

E-commerce merupakan satu set dinamis teknologi, 
aplikasi dan proses bisnis yang menghubungkan perusahaan, konsumen dan komunitas tertentu melalui transaksi elektronik dan perdagangan barang, pelavanan dan informasi yang dilakukan secara ekektronik.

\section{Triton (2006)}

E-commerce sebagai perdagangan elektronik dimana untuk transaksi perdagangan baik membeli maupun menjual dilakukan melalui elektronik pada jaringan internet.

Dalam pengertian lain, e-commerce adalah pembelian dan penjualan, pemasaran dan pelayanan serta pengiriman dan pembayaran produk, jasa dan informasi di internet dan jaringan lainnya antara perusahaan berjaringan dengan pelanggan, pemasok, dan mitra bisnis (Muhammad Ridwan dkk, 2021).

\section{Waterfall}

Menurut Pressman (2015:42), model waterfall adalah model klasik yang bersifat sistematis, berurutan dalam membangun software. Nama model ini sebenarnya adalah "Linear Sequential Model". Model ini sering disebut juga dengan "classic life cycle" atau metode waterfall. Model ini termasuk ke dalam model generic pada rekayasa perangkat lunak dan pertama kali diperkenalkan oleh Winston Royce sekitar tahun 1970 sehingga sering dianggap kuno, tetapi merupakan model yang paling banyak dipakai dalam Software Engineering (SE). Model ini melakukan pendekatan secara sistematis dan berurutan. Disebut dengan waterfall karena tahap demi tahap yang dilalui harus menunggu selesainya tahap sebelumnya dan berjalan berurutan. Fase-fase dalam Waterfall Model menurut referensi Pressman:

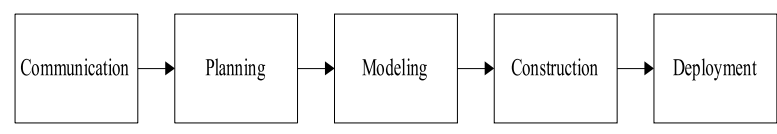

Gambar 1. Model Waterfall

\section{Communication (Project Initiation \& Requirements Gathering)}

Sebelum memulai pekerjaan yang bersifat teknis, sangat diperlukan adanya komunikasi dengan customer demi memahami dan mencapai tujuan yang ingin dicapai. Hasil dari komunikasi tersebut adalah inisialisasi proyek, seperti menganalisis permasalahan yang dihadapi dan mengumpulkan data-data yang diperlukan, serta membantu mendefinisikan fitur dan fungsi software.

\section{Planning (Estimating, Scheduling, Tracking)}

Tahap berikutnya adalah tahapan perencanaan yang menjelaskan tentang estimasi tugas-tugas teknis yang akan dilakukan, resiko-resiko yang dapat terjadi, sumber daya yang diperlukan dalam membuat sistem, produk kerja yang ingin dihasilkan, penjadwalan kerja yang akan dilaksanakan, dan tracking proses pengerjaan sistem.

\section{Implementation Modeling (Analysis \& Design)}

Tahapan ini adalah tahap perancangan dan permodelan arsitektur sistem yang berfokus pada perancangan struktur data, arsitektur software, tampilan interface, dan algoritma program. Tujuannya untuk lebih memahami gambaran besar apa yang akan dikerjakan.

\section{Construction (Code \& Test)}

Tahapan Construction ini merupakan proses penerjemahan bentuk desain menjadi kode atau bentuk/bahasa yang dapat dibaca oleh mesin. Setelah pengkodean selesai, dilakukan pengujian terhadap sistem dan juga kode yang sudah dibuat. Tujuannya untuk menemukan kesalahan yang mungkin terjadi untuk nantinya diperbaiki.

\section{Deployment (Delivery, Support, Feedback)}

Tahapan Deployment merupakan tahapan implementasi software ke customer, pemeliharaan software secara berkala, perbaikan software, evaluasi software, dan pengembangan software berdasarkan umpan balik yang diberikan agar sistem dapat tetap berjalan dan berkembang sesuai dengan fungsinya. (Pressman, 2015:17).

\section{HASIL DAN PEMBAHASAN}

\section{A. Hasil}

1. Analisa Kebutuhan

Dalam tahap ini menjelaskan sistem saat ini secara lengkap dengan menggambarkan proses bisnis yang sedang berjalan di UKM ini dan menggambarkan sistem informasi yang ideal (sistem yang diusulkan) dengan menggunakan flowchart.

Keterangan :

PO: Purchase Order

DO: Delivery Order

\section{Analisis sistem yang diusulkan}

Dalam tahap analisis ini yaitu menggambarkan sistem informasi yang ideal atau sistem yang diusulkan untuk UKM Ike Suti.

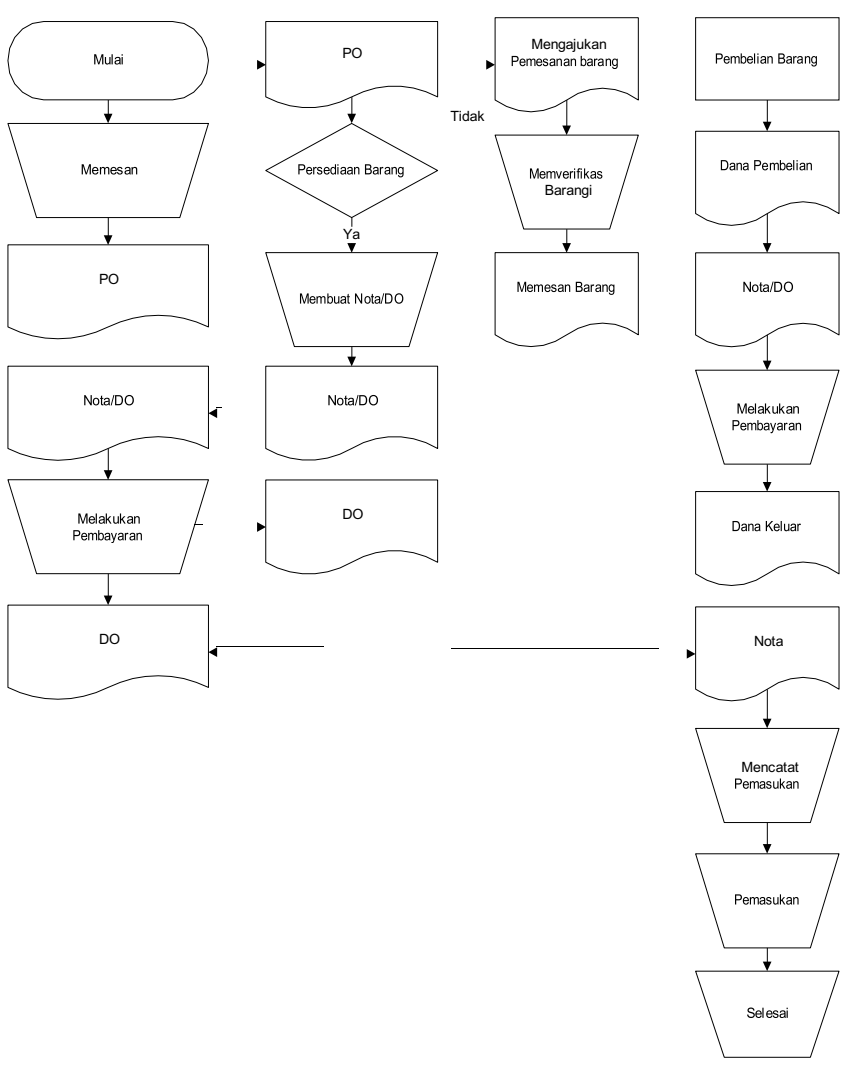

Gambar 2. Flowchart Kegiatan Konsumen dan Admin 


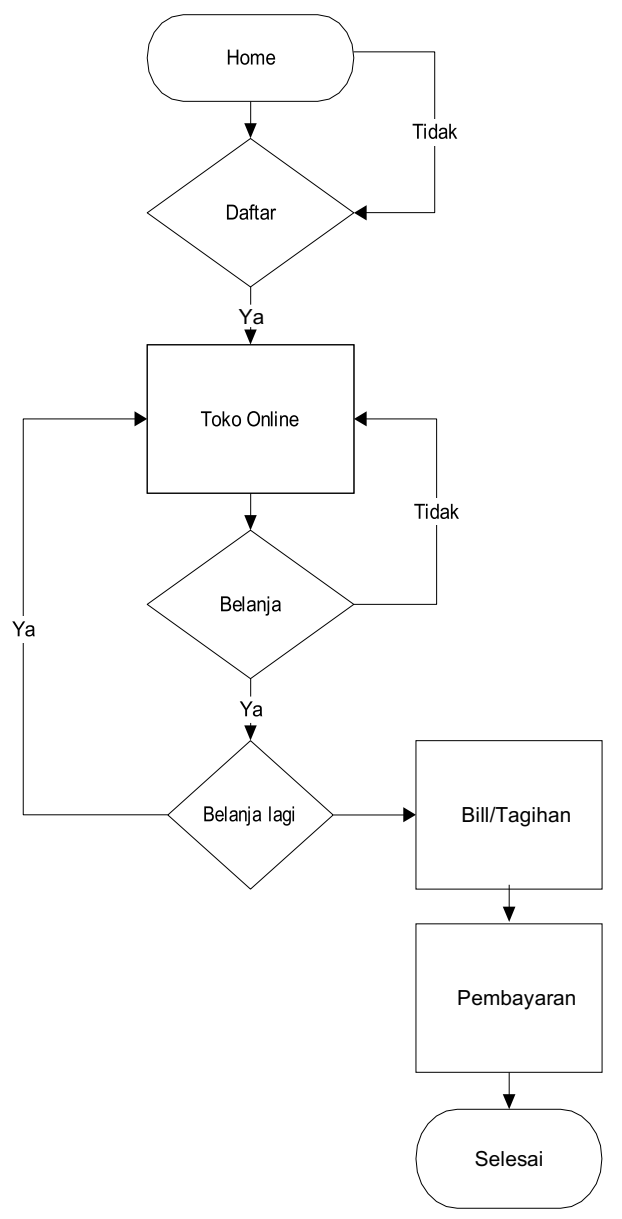

Gambar 3. Flowchart sistem usulan untuk pelanggan

Pada gambar 4.2.2, pelanggan mengisi username dan password, jika tidak terdaftar menjadi pelanggan, maka akan melakukan registrasi unutk mendaftar menjadi pelanggan dan mendapatkan username dan password, sehingga pelanggan tersebut bisa melakukan login, yang selanjutnya dapat melihat produk dan melakukan transaksi belanja, jika tidak melebihi transaksi anda, maka akan lanjut ke proses perhitungan transaksi dan mengisi atau merubah alamat kirim sampai memilih metode pembayaran yang akan terpilih, setelah memasukan metode yang dipilih, maka proses selanjutnya akan tampil bukti anda dan bisa dicetak untuk bukti pembelanjaan atau transaksi anda.

\section{Perancangan Sistem Entity Relationship Diagram (ERD)}

Entity Relationship Diagram (ERD) merupakan suatu model untuk menjelaskan hubungan antar data dalam basis data berdasarkan objek-objek dasar data yang mempunyai hubungan antar relasi. ERD untuk memodelkan struktur data dan hubungan antar data, untuk menggambarkannya digunakan beberapa notasi dan symbol.

Dalam website sistem penjualan online ini penulis mencoba membat rancangan ERD yang akan menghubungkan antara konsuen, produk, admin sebagai pengolah website serta data produk dan supplier sebagai supplier produk. Untuk rancangan ERD website sistem informasi penjualan online ini adalah sebagai berikut

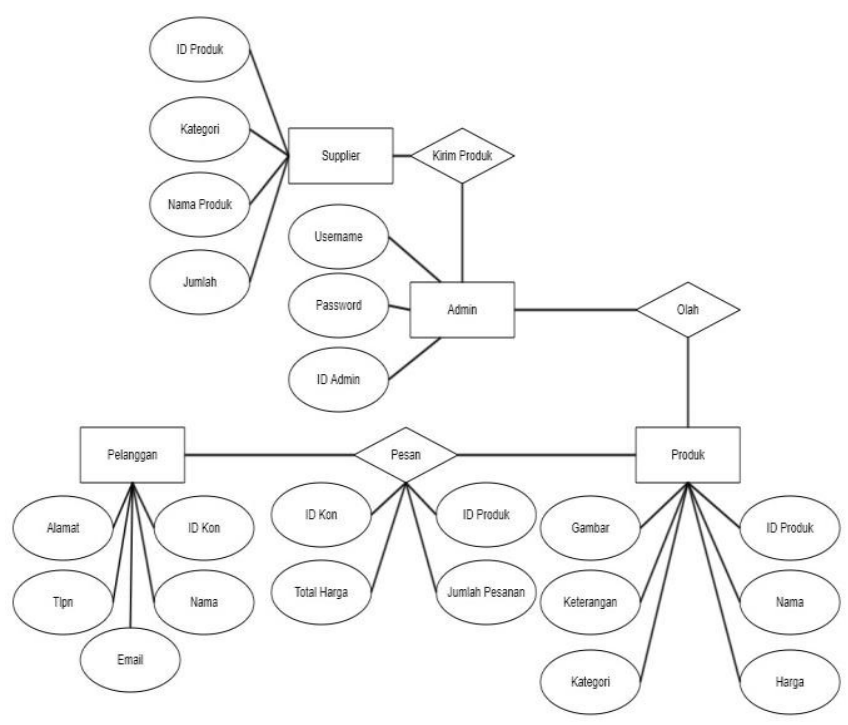

Gambar 4. Entity Relationship Diagram (ERD) Sistem Penjualan Online

\section{Database Relasi}
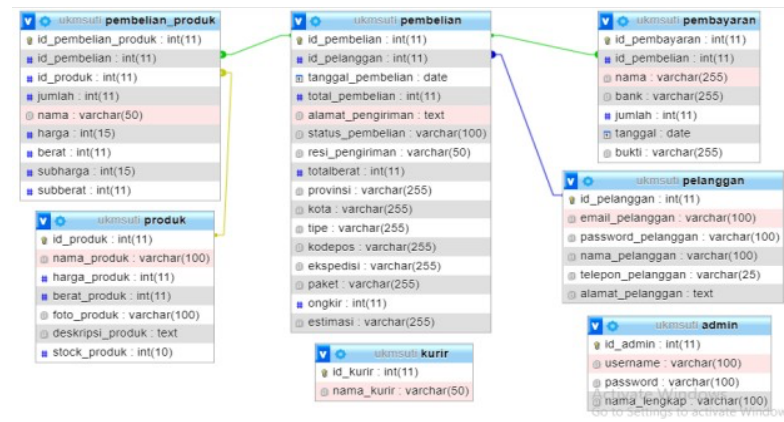

Gambar 5. Relasi Antar Tabel

\section{B. Pembahasan}

Sistem penjualan online berbasis e-commerce pada UKM Ike Suti adalah sebuah sistem penjualan online yang dikembangkan untuk membantu pelanggan pada UKM dalam transaksi jual beli roduk yang terdapat pada UKM tersebut. Sistem penjualan online ini dikembangkan dengan menggunakan bahasa pemrograman $P H P$, MariaDB, XAMPP, dan sublime Text. Sistem penjualan ini dikembangkan dengan cara melakukan pendekatan dengan pemilik UKM dalam menjalankan transaksi jual beli dan cara mempromosikan produknya.

Sistem penjualan online ini merupakan web yang akan dikelola oleh pemilik UKM dan user (pengguna). User akan berinteraksi dengan sistem dengan cara mendaftarkan diri sebagai pelanggan dan pemilik UKM beriteraksi sebagai admin atau pengelola sistem yang digunakan.

\section{Halaman Login Admin}

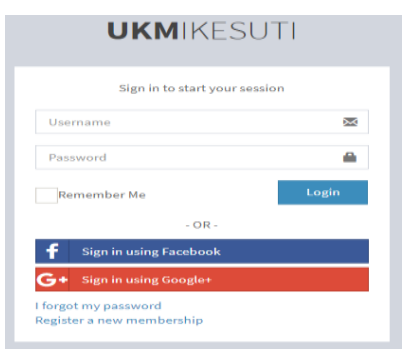

Gambar 6. Halaman Login Admin 
2. Halaman Halaman Home Admin

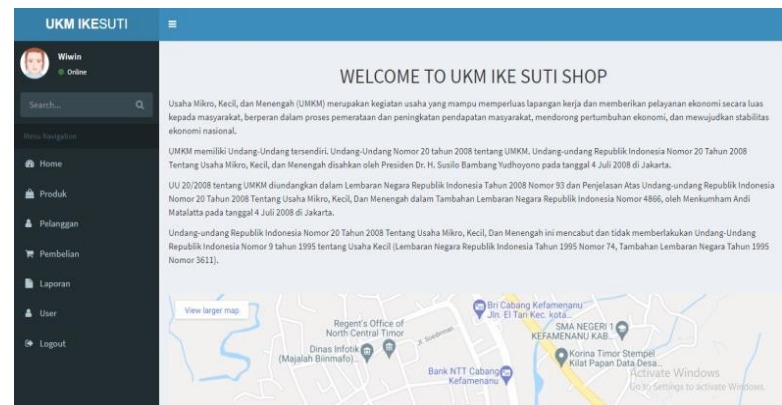

Gambar 7. Halaman Home Admin

3. Halaman Halaman Produk Admin

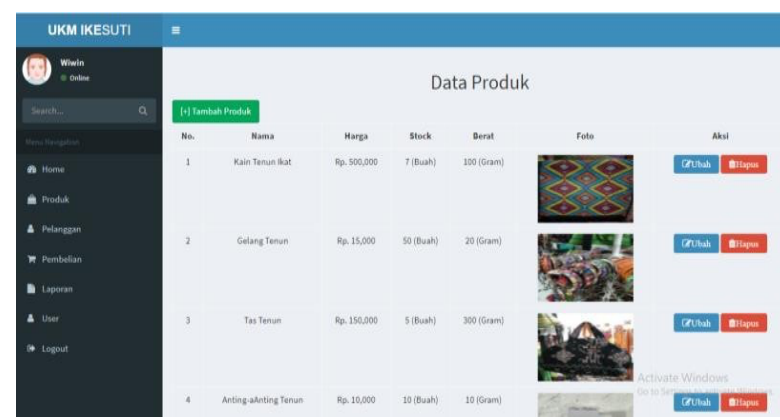

Gambar 8. Halaman Produk Admin

4. Halaman Halaman Pelanggan Admin

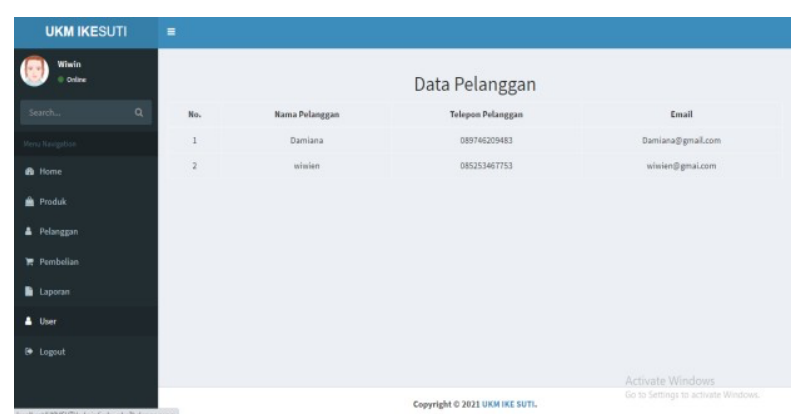

Gambar 9. Halaman Pelanggan Admin

5. Halaman Halaman Data Pembelian Admin

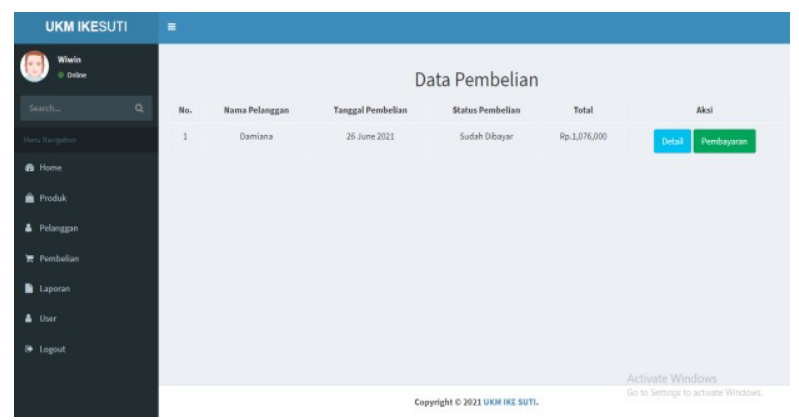

Gambar 10. Halaman Data Pembelian Admin

6. Halaman Halaman User Admin

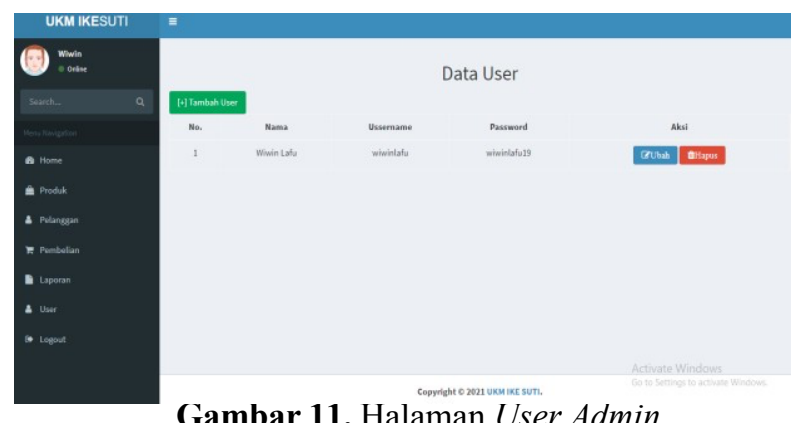

7. Halaman Beranda Pelanggan
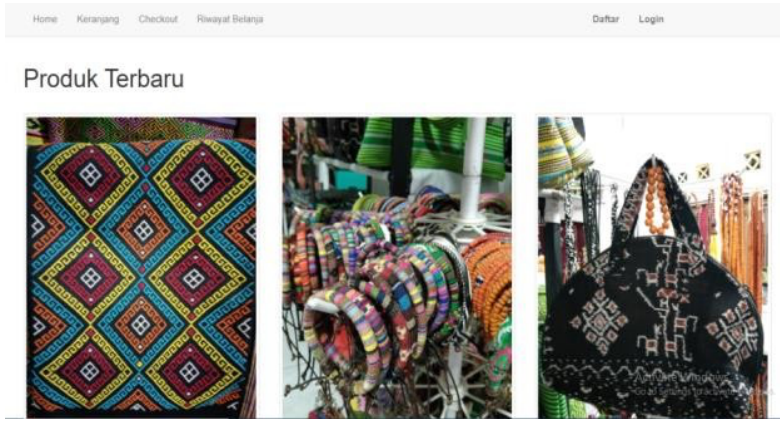

Gambar 12. Halaman Beranda Pelanggan

8. Halaman Daftar Pelanggan

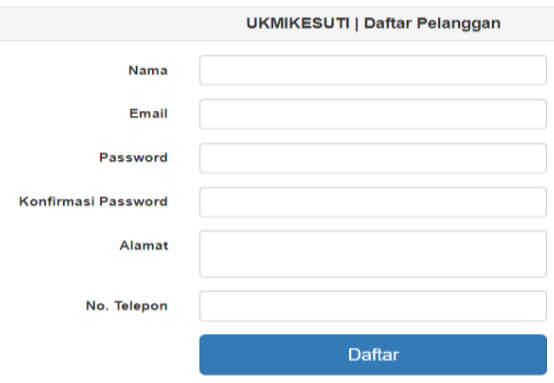

Gambar 13. Halaman Daftar Pelanggan

9. Halaman Login Pelanggan

\begin{tabular}{l} 
UKMIKESuti | Login \\
Email \\
\hline Dogin \\
\hline Daftar Sebagai Pelanggan ? Daftar
\end{tabular}

Gambar 14. Halaman Login Pelanggan

\section{IV.KESIMPULAN}

Dari pembahasan yang sudah diuraikan maka penulis mencoba membuat kesimpulan seperti berikut ini:

1. Proses bisnis implementasi sistem penjualan online berbasis e-commerce dapat dilakukan secara mudah dengan aplikasi ini. Sistem ini memiliki kemudahan untuk memasarkan san menjual produk memiliki kemudahan untuk memesarkan dan menjual produk milik perusahaan dengan proses $\mathrm{ukm}$ dengan proses transaksi jual beli produk yaitu melalui pembayaran secara langsung.

2. Dengan adanya web e-commerce yang memanfaatkan internet sebagai media pemasaran, dapat memudahkan pemilik toko untuk memberikan pelayanan terhadap konsumen/pelanggan secara optimal dan memberikan informasi 24 jam serta dapat diakses kapan saja dimana saja.

\section{DAFTAR PUSTAKA}

[1]. Berek M., G., dkk. 2019. Rancang Bangun Aplikasi Pencairan Perguruan Tinggi. Jurnal SCRIPT Volume 7 Nomor 2. AKPRIND Yogyakarta. 
[2]. Februariyanti H., \& Zuliarso E., 2012. Rancang Bangun System Perpustakaan Untuk Jurnal Elektronik. Jurnal Teknologi Informasi DINAMIK Volume 17 Nomor 2. Universitas Stikubank.

[3]. Hani Atun Mumtahana, dkk. 2017. Jurnal Ilmu Komputer Dan Informatika Pemanfaatan Web ECommerce Untuk Meningkatkan Strategi Pemasaran. Universitas PGRI Madiun.

[4]. Hastanti R., P., dkk. 2015. System Penjualan Berbasis Web (E-Commerce) Pada Tata Distro Kabupaten Pacitan. Jurnal Bianglala Informatika Volume 3 Nomor 2. Universitas Surakarta, STMIK Nusa Mandiri Jakarta, STKIP PGRI Pacitan.

[5]. Lesmono I., D., 2018. Rancang Bangun System Informasi Penjualan Sepatu Berbasis Website Dengan Metode Waterfall. Jurnal SWABUMI Volume 6 Nomor 1. AMIK BSI Purwakerto.

[6]. Muhammad Raja Fadhilah, dkk. 2018. Perancangan dan Implementsi database server dengan MariaDB dan Linux Centos. Universitas Telkom, Volume 4 Nomor 3.

[7]. Ridwan M., dkk. 2021. Jurnal Teknologi Informasi dan Komunikasi: Rancang Bangun Marketplace Berbasis Website Menggunakan Metodologi System Development Life Cycle (SDLC) Dengan Model Waterfall. Vol. 5 No. 2. 